\title{
Mass of on line innovative talent training mode for theory of probability and mathematical statistics teaching reform
}

\author{
Donghong ZHAO \\ Department of Applied Mathematics,School of Mathematics \\ and Physics,University of Science and Technology \\ Beijing,100083,China \\ Email: zdh751111@ustb.edu.cn
}

\author{
Li Liu \\ The higher institute of engineers of \\ University of Science and Technology \\ Beijing,100083,China \\ Email:liliu@ustb.edu.cn
}

\begin{abstract}
From the teaching content, teaching means and teaching design and teaching way four aspects of teaching reform of the course of the theory of probability and mathematical statistics, in-depth studies are pointed out that the theory of probability and mathematical statistics should pay attention to the theory with practice, in the case of the application in mathematical modeling of thought and engineering background, and strengthen students' practical teaching link, cultivate the students' engineering application ability, at the same time the Internet is busy recently the emergence of network course, in the aspect of classroom teaching should make some research of how to deal with, this article made some discussion.
\end{abstract}

Keywords-Probability and mathematical statistics; Course design mode; Engineering background; case

\section{INTRODUCTION}

With the development of social progress, probability and statistics in the field of engineering applications increasingly appear its importance.

Probability and statistics is widely used in the operation of the large system engineering control and inspection for the forecast of the future world, providing the basis of the quantitative analysis for decision makers make decisions. Abstract, probability and statistics, however, the subject theory is used is not advanced mathematics knowledge, but the students don't know why to learn to use common reaction. This requires that we have to think, how to strengthen the perception of the students to the idea of probability and statistics? How to enhance students' ability of applying the idea of probability and statistics to solve practical problems? Therefore, it is necessary for the existing teaching mode, teaching method, teaching content for further discussion.

\section{PRELIMINARY DisCUSSION ON THE TEACHING CONTENT}

Our school in excellence in engineering education background, the higher institute of engineers has been reflected in all courses in the engineering background of the thought of mathematical modeling, the past teaching content more theoretical study and research, light practice. The engineering, economic management is memorization formula, in computation. At the same time, due to the amount of class time compression, the more probability of heavy and light statistics part of the content, let the student feel learning this course in the real meaning of life, leading to students feel boring, boring, tired of complex. Even frequently in the teaching content is inserted reflect social life care about some practical problems, such as game, ranking the sickbed arrangement, the recruitment employment statistics, life insurance and other issues. And the students themselves:

Here, the test index is the thickness of the sheet. Machine for factors, different three machines is a factor of three different levels; we assume that in addition to machine this factor,

\begin{tabular}{|lcc|}
\hline machine1 & machine2 & machine3 \\
\hline 0.236 & 0.257 & 0.258 \\
0.238 & 0.253 & 0.264 \\
0.248 & 0.255 & 0.259 \\
0.245 & 0.254 & 0.267 \\
0.243 & 0.261 & 0.262 \\
\hline
\end{tabular}

material specification, the level of the operators, and other conditions are the same. This is the single factor experiment; the purpose of the test is to examine the thickness of the plate produced by the machine with and without significant difference and namely the inspections machine the presence of significant influence factors on the thickness. If there is a significant difference thickness, suggests that the factors influencing the thickness of the machine are significant. Through the practice has proved that indeed was welcomed by the students, the students think that class is full, feel under the theory of probability and mathematical statistics and they want to learn professional has very close connection, greatly increase the 


\section{A PRELIMINARY DISCUSSION OF THE TEACHING}

Now teaching mode to overcome the inherent pattern of the traditional teaching method, the original teaching model is to define - theorem - sample - practice - homework "teaching mode. From this semester in March, 2011, in the higher institute of engineers set up separately, probability theory and mathematical statistics platform has the characteristics of fewer class small, we in the teaching, we try to practice teaching mode, make the theory with practice, our research results in the light of the features of the four professional engineer college students and further reform and in-depth, and that there is a new interpretation of probability and mathematical statistics.

Probability theory and mathematical statistics" is relatively higher mathematics in all subjects combined with practical production and daily life most closely. In course teaching should pay attention to the theory with practice, emphasis on applications into the mathematical simulation experiment in the thoughts of the new teaching method to cultivate students' innovation ability. Appropriate reform the classroom teaching methods, explore the new teaching mode, to strengthen students' practical teaching link, develop the students' ability of application and innovation.

We according to the theory of probability and mathematical statistics course content and the method is discussed and the research, obtained many results and experience, also has obtained certain achievement. In the classroom of teaching of probability and statistics in nearly a year we take the class four modules, including "learn, speak, practice, evaluation of" four big modules, each module, the proportion of time in class and should be, because of the raw and well.

"Learning", it is show the learning objectives, pointed out the emphases and difficulties of learning, learning methods, students through the collective learning and self-study, cooperative learning group, such as form, to master learned information. "Speak", is the key and difficult, error-prone points, easy to mix and funneled easily, the thinking, strategies, methods, rules, techniques, ideas, feelings, attitudes, qualities, experience, etc., prompting students understanding and the understanding to promote to a higher level and state, the church student learning and thinking.

"Practice", is the classroom training, inspection study effect, guides the student to consolidate and deepen the knowledge, deepen the understanding of the content and comprehension. "Rating", it is through self-evaluation, mutual, teachers review methods such as reverse in a timely manner. Feed students have mastered the content, correct mistakes, summarize method, and reveal patterns. Through such a process not only can stimulate students' interest in learning and innovation spirit, but also can cultivate the students' scientific research ability

\section{DisCUSSION ON THE TEACHING METHODS}

Implementation of diversified teaching method, the pure teacher-centered, with the center of the classroom teaching mode reform is student-centered, guide students to play a leading role in class, mainly through self-evaluation of students, mutual, teachers review methods such as feedback students have mastered the content, correct mistakes, summarize method, reveal the law of greatly improving the students, the director of the initiative. Bayesian formula is an important formula in probability theory, it combines the conditional probability formula, multiplication formula and a formula of full probability, has a broad application.

To stop in tedious formula derivation and calculation, we introduce an example of this. Talking about full probability formula and bayes formula, let the students use the bayesian formula analysis Aesop's fables "children and Wolf" "1" in psychological activities of the villagers. Group discussion, students under the guidance of teachers, to make the following analysis: first, assume that the villagers impression of the child, he said a lie (A1) and speak the truth (A2) the same probability, namely set $\mathrm{P}(\mathrm{A} 1)=0.5$,

$\mathrm{P}=0.5$, (A2) suppose lie children shouted "Wolf" (for B), the probability of Wolf is 0.3 , tell the truth the children shouted "Wolf", the probability of Wolf is 0.8 . When villagers went up into the mountain to play for the first time the Wolf found the Wolf didn't come, the villagers to lie the understanding of the child. This suggests that the villagers said to the child lies the probability changed from 0.5 to 0.7778 . The villagers after twice yesterday, said to the child lies the probability of from 0.5 to 0.9245 , namely ten nine sentences is false, the impression with the villagers, how farewell when they heard the third call up the mountain play the Wolf?

By this kind of case study, the students can experience personally using the process of probability and statistics knowledge to solve practical problems, generate ideas, to apply the deepening understanding of probability and statistics knowledge, forming a virtuous circle, further strengthen the consciousness of their application and interest in learning, in turn, promote the students take the initiative to learn theoretical knowledge of the course of the theory of probability and mathematical statistics.

Teaching methods to explore new teaching mode in order to make the students' classroom learning to achieve better effect, not only pay attention to the instance on the teaching content, and in the teaching method is to continuously explore new teaching mode. Teachers should abandon "against hall to fill" the teaching method, using exploratory, hierarchical teaching such as teaching mode, imparting knowledge unit 1.

IV Main features

\section{A. Pay attention to add instance in probability teaching, teaching content increased}

In normal teaching outline, we don't need to tell the content of the regression analysis, we study the teaching process in the case of does not affect other content add this part to come in, try to give the students list some topics related to their field, and to absorb and blend in with the actual problems in the 
teaching content on the applied subject. Through practice has proved that indeed was welcomed by the students, the students think that class is full, feel under the theory of probability and mathematical statistics and they want to learn the professional has a very close connection, greatly increased the enthusiasm of learning, and learning motivation.

\section{B. The innovation of the teaching means}

The traditional teaching method use "definition - more theorem - sample - practice - operations" mode of teaching, students often make it difficult to understand the definition of the objective background and discover the thinking process of theorem. Although we do not have conditions directly in the classroom for everyone to use MATLAB to achieve, as much as possible, but we can use MATLAB to realize in the PPT show up, let us go back to their implementation.

\section{The mathematical idea of combining practice with your classmates}

Implementation of diversified teaching mode, therefore, is simply to teachers as the center, with the center of the classroom teaching mode reform is student-centered, guide students to play a leading role in class, mainly through selfevaluation of students, mutual, teachers review methods such as feedback students have mastered the content, correct mistakes, summarize method, reveal the law of greatly improving the students, the director of the initiative.
D. With the professional characteristics of a higher institute of engineers, in the teaching with some engineering cases

In the teaching of probability, we introduced some of the students and their professional related probability calculation; we made some attempts, in this respect, for example, on the application in some engineering background.

\section{ACKNOWLEDGMENT}

Beijing university of science and technology teaching reform project, funded number :JG2014M42;KC2013YJX17; JG2011Z13; JYBZYSD201207; JG2011ZB02, at the same time also gives 2012 Beijing municipal educational reform project "top creative talent training mode of research"

\section{REFERENCES}

[1] Zhao Donggong, li na, Zhao Xiangkui, fu-cheng liao. Mathematical simulation experiment in the teaching of probability theory and mathematical statistics, higher science education,2010(2) : 175 - 177.

[2] R.Bellman.Introduction to Matrix Analysis. New York: McGrawHill,1970.

[3] Tongji university applied mathematics. Engineering mathematics. Shanghai: tongji university press, 2002.

[4] L.A.Hagman,D, M . Young. Applied Interactive Methods. New York/London: Academic Press,1981.

[5] pei-hong cheng, jin-xia wang "outstanding engineers training oriented theoretical physics curriculum reform. Journal of ningbo college of engineering, vol. 24, No. 2, 23-27.

[6] Shi-liang sun. Some typical problems in probability theory. The university mathematics, 2008 (1) : 155-161.

[7] trail poem loose. Probability and mathematical statistics [M]. Beijing: China statistics press, 2000

[8] piaget's genetic epistemology principle [M]. Beijing: the commercial press, 1987, P13. 